\title{
Detection of $E$. coli in beach water within 1 hour using immunomagnetic separation and ATP bioluminescence
}

\author{
JiYoung Lee and Rolf A. Deininger \\ Department of Environmental Health Science, School of Public Health, University of Michigan, 109 S. Observatory, Ann Arbor, MI \\ 48109, USA
}

Received 5 November 2003; revised 3 December 2003; accepted 5 December 2003

\begin{abstract}
The contamination of beach waters occurs from the discharge of storm water and sanitary sewer overflows containing faecal material. Additional faecal material derives from discharge of animals and waterfowl. In order to protect public from exposure to faecal-contaminated water, it is required to test enteric indicators in beach water. The problem is that the traditional culture-based methods cannot meet this goal because it takes too long $(>24 \mathrm{~h})$, so the results are not available until a day later. A rapid method for testing beach water for Escherichia coli within $1 \mathrm{~h}$ has been developed. Immunomagnetic separation (IMS) and ATP bioluminescence were used for selective capture and quantification, respectively. This rapid method was compared to the current method (m-TEC) using beach water samples. The beach samples were prefiltered with a $20 \mu \mathrm{m}$ pore size filter in order to remove algae, plant debris and large particles. The results showed that the prefiltration step did not trap the bacteria which were present in the original water samples. The prefiltered water was then passed through a $0.45 \mu \mathrm{m}$ pore size filter for concentration. The deposited bacteria were resuspended and then mixed with superparamagnetic polystyrene beads (diameter of $0.6 \mu \mathrm{m})$ that were coated with E. coli antibodies. After IMS, the quantification of the E. coli was done by ATP bioluminescence. The results obtained with IMS-ATP bioluminescence correlated well with the plate count method $(\mathrm{Rsq}=0.93)$. The detection limit of the assay was about $20 \mathrm{CFU} / 100 \mathrm{~mL}$, which is well below the US EPA limits for recreational water. The entire procedure can be completed in less than 1 hour. The necessary equipment is portable and was tested on-site. Copyright @ 2004 John Wiley \& Sons, Ltd.
\end{abstract}

KEYWORDS: Escherichia coli; beach; immunomagnetic separation; ATP bioluminescence; rapid method

\section{INTRODUCTION}

In order to assure the safety of bathing beaches at rivers and lakes across the country, recreational waters are routinely monitored for faecal pollution using Escherichia coli as an indicator organism for freshwater beaches, which was recommended by the US Environmental Protection Agency (US EPA). The current standards for beach water require that the geometric mean of the bacterial densities should not exceed 126 CFU/100 mL (generally not less than five samples, equally spaced over a 30 day period), and that no single sample should exceed $300 \mathrm{CFU} / \mathrm{mL}$ (1). The current culture-based test method (e.g. m-TEC agar) takes about $24 \mathrm{~h} \mathrm{(2).} \mathrm{Thus,} \mathrm{there} \mathrm{is} \mathrm{always} \mathrm{a} \mathrm{time} \mathrm{delay} \mathrm{(}>24 \mathrm{~h}$ ) between a sample collection and the availability of the results. The closure of beaches based upon the test results of 1 day previously is not adequate for the protection of swimmers from possible health risks. It also causes delay in reopening the beaches, which is not in the public's best interest.

*Correspondence to: J. Y. Lee, Department of Environmental Health Science, School of Public Health, University of Michigan, 109 S. Observatory, Ann Arbor, MI 48109, USA.

E-mail: jylee@umich.edu

Contract/grant sponsor: Michigan Department of Environmental Quality, USA. Contract/grant number: GL 00-059.
The need for a faster method that provides timely results of $E$. coli concentrations has been widely recognized among responsible health departments. The desirable testing method should meet the following criteria: it should be fast, sensitive, simple, quantitative, portable and be correlated well with the current methods.

Recently, several rapid assays for detecting E. coli have been explored. They included polymerase chain reaction (PCR)-based method (3), fluorescent in situ hybridization (FISH) (4) and an enzymatic method ( $\beta$ D-glucuronidase) (5). These methods are highly specific but can only be performed in a laboratory and require a well-trained staff. PCR-based assays have problems in the quantification of microorganisms from the natural environment (6). Another limitation in using PCR for the analyses of beach samples is interference in the reaction by substances that are present in the samples, such as humic substances and colloid matter (7). Another disadvantage is that this procedure also does not differentiate between dead and living bacteria. The FISH method has a problem in counting true E. coli under the microscope, because bacteria in water are often starved or stressed, which results in tiny cells, which are difficult to distinguish among some material which may bind probes non-specifically (8). The tiny cells are hard to enumerate unless a treatment with antibiotics (e.g. 
nalidixic acid or ciprofloxacin) is employed to enlarge the cells. When a volume of water is passed through a filter, all bacteria in that volume are supposed to be on the filter. However, counting the whole filter surface under the microscope is hard to achieve. Using a scanning machine (e.g. a laser scanning cytometer) to count the whole filter surface for fluorescent objects could be another alternative.

In our study, immunomagnetic separation (IMS) and ATP bioluminescence were used for the selective capture of target bacteria and their quantification, respectively. This procedure meets all the criteria that have been mentioned previously. The IMS utilizes uniform superparamagnetic polystyrene beads coated with antibodies that bind to the desired bacterial population, forming a bead-bacteria complex that is easily separated from the heterogeneous bacteria suspension by exposure to a magnetic field. IMS has been documented as a useful separation tool for downstream applications, such as DNA analysis (9), flow cytometry (10) and plate count (11). ATP bioluminescence was employed for the estimation of the bacteria in a sample after separation of target bacteria by IMS. The estimation of the bacterial numbers with the ATP bioluminescence method is known to be highly correlated with the plate count method $(12,13)$ and direct viable count (12) and estimates bacterial concentrations within minutes. An additional advantage of this method is that it only counts viable bacteria (2). The aim of this study was to evaluate the results of the rapid method for E. coli in beach water and compare it with the conventional method. Beach water samples were collected by cooperating health departments from two Great Lakes beaches, two inland beaches and the Huron River, located in southeast Michigan.

In order to remove plant debris and particles, a prefiltration step was used. Various types of prefilters were tested to find the optimal pore size and the best material for a prefilter that effectively removed particles while minimizing bacterial loss. A $20 \mu \mathrm{m}$ nylon filter membrane served this purpose in these experiments. In the final stage of the study, the method was tested on-site at a beach. The entire procedure can be completed within an hour. The bacteria captured by E. coli antibody-coated magnetic beads were identified to test the specificity of the procedure.

\section{MATERIALS AND METHODS}

\section{Collection of beach water samples}

Beach samples $(\sim 1 \mathrm{~L})$ were collected in an autoclaved polypropylene container, 1 foot below the surface, in water 3-6 feet deep, by the cooperating health department personnel in south-east Michigan during their regular sampling schedule, and provided additional samples for this study. The collected samples were kept in a cooler with ice and were transported to the laboratory within $2 \mathrm{~h}$. The beach samples were collected from two Great Lakes beaches (Lake St. Clair and Lake Erie), two inland beaches (Independence Lake and Byram Lake) and the Huron River from June to August 2001.

\section{Concentration of bacteria by serial filtration}

Prefiltration was used to remove large particles and algae from the water sample, which may interfere in the analyses. Various filtration methods and set-ups were investigated to find the simplest and most effective method for prefiltering the water samples. The prefilter material used for the first testing included a glass fibre filter, a $5 \mu \mathrm{m}$ pore size nylon filter, and a nylon filter with a nominal pore size of $20 \mu \mathrm{m}$. A $47 \mathrm{~mm}$ glass fibre filter was used with no nominal pore size rating. Based upon these test results of the prefilters, the $20 \mu \mathrm{m}$ nylon filter (Osmonics, Minnetonka, MN, USA) was chosen. This filter removed particles efficiently and allowed passage of the bacteria present in the beach water samples.

The water sample was drawn through the filters by either a hand-powered or an electric vacuum pump which was set for a vacuum of $15 \mathrm{inHg}$. The power supply consisted of either a $110 \mathrm{~V}$ main or a portable battery. The filtration volume was $100-500 \mathrm{~mL}$. The final filtration for concentrating the bacteria that passed through the prefilter was accomplished with a $0.45 \mu \mathrm{m}$ membrane that retained $E$. coli as well as a number of other microorganisms. The filter membrane was held in a $47 \mathrm{~mm}$ filter holder (Pall, Ann Arbor, MI, USA) that was directly connected to the prefiltration device. A disposable prefiltration device (Millipore, Bedford, MA, USA) was used to make the procedure more fieldapplicable.

\section{Preparation of the antibody-coated magnetic beads}

The antibodies were selected based upon the following criteria: (a) range of specificity; (b) type of antigen to raise the antibodies; and (c) cost. Antibodies targeted against all environmental strains of $E$. coli hardly exist, because the types of $E$. coli in the natural environment are quite diverse. For the detection of E. coli in beach water, polyclonal antibodies were used instead of monoclonal antibodies to capture a broader range of target organisms. The antibodies were purchased from Biodesign International (Saco, ME, USA). The type of antigen to raise antibodies was heat-killed sonicate of whole cell E. coli, rather than a specific antigen, such as lipopolysaccharide, $\mathrm{O}$ antigen or $\mathrm{K}$ antigen. They target a broader range of $E$. coli in the environment. The manufacturer indicated that the antibodies may 
cross-react with Enterobactericeae such as Shigella and Salmonella. Thus, some of the bacteria captured may not be $E$. coli but are still part of the enteric group. Since E. coli are indicator organisms of faecal contamination, a few other captured species do not change the intent of the test.

Magnetic beads were purchased from Bangs Labortories (Fishers, IN, USA). The magnetic beads were disinfected with $0.1 \%$ sodium azide and were rinsed with sterile distilled water three times before they were mixed with the antibodies.

The amount of antibodies and magnetic beads to achieve surface saturation was calculated following the manufacturer's instructions described in TechNote No. 204 (Bangs Laboratories, Fishers, IN, USA).

To assure the correct spatial orientation with minimal likelihood of non-specific binding, a three-fold excess of the antibodies was employed. The manufacturer recommends adding antibodies in a $3-10 \times$ excess of the calculated monolayer. The median diameter of the chosen beads was $0.6 \mu \mathrm{m}$.

Magnetic beads [0.2 mL of $10 \%$ (wt) solid contents] were coated with $0.14 \mathrm{~mL}$ anti-E. coli antibodies (the original concentration of antibodies was $3 \mathrm{mg} / \mathrm{mL}$ ) and $0.66 \mathrm{~mL}$ PBS ( $\mathrm{pH}$ 5.5). The adsorption procedure was adapted from the passive adsorption method (TechNote No. 204, Bangs Laboratories, Fishers, IN, USA). The suspension was mixed for $1 \mathrm{~h}$ at $60 \mathrm{rpm}$ (Dynal Sample Mixer, Dynal, Lake Success, NY, USA) at room temperature. The beads were then removed from the solution with a magnet and resuspended in $0.8 \mathrm{~mL}$ PBS, and then rinsed again in $0.2 \mathrm{~mL}$ PBS ( $\mathrm{pH}$ 7.4). The antibodybead complex was stored in $0.2 \mathrm{~mL}$ PBS with $1 \%$ BSA at $4^{\circ} \mathrm{C}$ until they were used. The prepared antibodybeads were used within 2 weeks.

\section{Selective capture and measurement of $E$. coli}

The trapped organisms were washed from the final membrane either via resuspension in Tween 20containing PBS $(10 \mathrm{~mL})$ or by back-flushing with a syringe while still in the filter holder. The two methods did not show a significant difference ( $t$-test, $p>0.05)$ during the preliminary study. E. coli-antibody coated beads $(0.1 \mathrm{~mL})$ were added to that tube, and mixed for 15 min at $60 \mathrm{rpm}$ with a mixer (Dynal, Lake Success, NY). In order to test this procedure in the field, a battery-operated portable sample mixer was built. During mixing, the antibody-coated beads bind the target bacteria and form bead-bacteria complexes. Using a magnetic separator, these complexes were concentrated to the magnet side of the tube wall. The supernatant was discarded while the tube was on the magnet. The beadbacteria complexes were resuspended in a PBS solution $(10 \mathrm{~mL})$. The separation and washing steps were repeated twice.
At the final washing step, the entire pellet was resuspended in $1 \mathrm{~mL}$ PBS and transferred to a microcentrifuge tube. After magnetic separation using a small magnetic separator, the PBS was discarded and $50 \mu \mathrm{L}$ somatic cell releasing agent [New Horizons Diagnostics (NHD), Columbia, MD, USA] was added to remove any possible ATP from non-bacterial cells. After magnetic separation, the liquid portion was removed by pipetting and the pellet was washed with PBS (0.2 mL). After magnetic separation, the buffer was discarded. A bacterial releasing agent $(50 \mu \mathrm{L})$ was added to rupture the bacterial cells and magnetic separation was done to remove the magnetic beads. At this stage, all the ATP that was extracted from the E. coli was contained in the liquid portion. The entire liquid was then transferred to a cuvette. The enzyme/substrate, luciferin and luciferase $(50 \mu \mathrm{L})$, for light development were added and the light emission was measured in relative light units (RLU) with a microluminometer (Model 3550, NHD, Columbia, MD, USA). The RLU value is solely due to the ATP of the E. coli. The RLU values were converted to RLU/100 mL after dividing with the filtered volume of water. The activity of luciferin and luciferase was checked with a standard ATP solution (NHD, Columbia, MD, USA) according to the manufacturer's instructions. Figure 1 summarizes all the steps. All the tests were performed in triplicate and a blank control was done with PBS.

\section{Determination of the specificity of the antibodies}

In order to test the specificity of the antibodies, the bacteria captured by IMS in beach water samples were identified using a genetic fingerprinting method and a biochemical analysis procedure; these methods were Riboprinter (Qualicon, Wilmington, DE, USA) and rapid API 20E (bioMerieux, Hazelwood, MT, USA), respectively. Beach water samples were filtered with the same procedure of IMS and the suspension was then passed through a $0.45 \mu \mathrm{m}$ filter membrane. The filter membranes were placed on $\mathrm{m}$-TEC plates and incubated $\left(35^{\circ} \mathrm{C}\right.$ for $2 \mathrm{~h}$, then $44.5^{\circ} \mathrm{C}$ for $\left.22 \mathrm{~h}\right)$. All the yellow colonies from the m-TEC plates, which contained about 30 colonies or so, were streaked onto nutrient agar plates and serially subcultured to check purity. From 20-24 h cultures, colonies were inoculated into a buffer (Riboprinter) and $0.85 \% \mathrm{NaCl}$ solution (rapid API $20 \mathrm{E})$. The remaining procedure followed the manufacturers' instructions. The beach samples for the identification were randomly chosen.

\section{Comparison with traditional method}

Once samples had arrived at the laboratory the samples were processed, employing the conventional m-TEC 


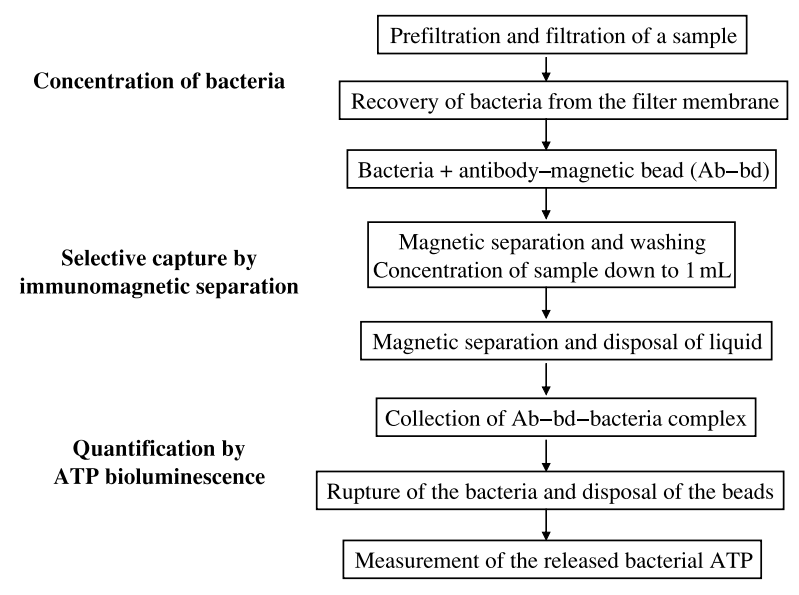

Figure 1. Summary of the analysis procedure for E. coli detection in a beach water sample.

(Becton Dickinson, Sparks, MD, USA) membrane filtration method and the new rapid method, IMS-ATP bioluminescence. The participating health departments tested the same set of the beach samples from two Great Lake beaches and two inland beaches using the same traditional method. The yellow colonies were counted after incubation at $35^{\circ} \mathrm{C}$ for $2 \mathrm{~h}$ and $44.5^{\circ} \mathrm{C}$ for $22 \mathrm{~h}$.

\section{RESULTS AND DISCUSSION}

The participating health departments in south-eastern Michigan provided us with beach samples during their regular beach monitoring schedule. The received samples were processed employing both the traditional method (membrane filtration using m-TEC agar) and the IMS-ATP bioluminescence in our laboratory. The same samples were tested by the health departments using the m-TEC method. For the purpose of quality assurance, the E. coli results obtained by the traditional m-TEC method were compared between the two laboratories: University of Michigan (UM) vs. cooperating health departments. Comparative results for the laboratories demonstrated excellent agreement (Figure 2). The concentration of E. coli was in the range 1-700 CFU/ $100 \mathrm{~mL}$ (UM result). The highest concentration was found at Lake St. Clair Memorial Park Beach, while the lowest concentration was detected at Streling Park Beach. None of the cases exceeded $126 \mathrm{CFU} / 100 \mathrm{~mL}$, the US EPA 30-day average standard (geometric mean of more than five samples equally spaced over a 30-day period) and one of the 24 samples tested exceeded the US EPA single sample limit (300 CFU/100 mL).

Prefiltration of beach water samples was required for the removal of algae and other suspended solids. An initial concern of the prefiltration was that a number of $E$. coli would be lost by prefiltration from the original sample. Various prefilters were tested for the perform-

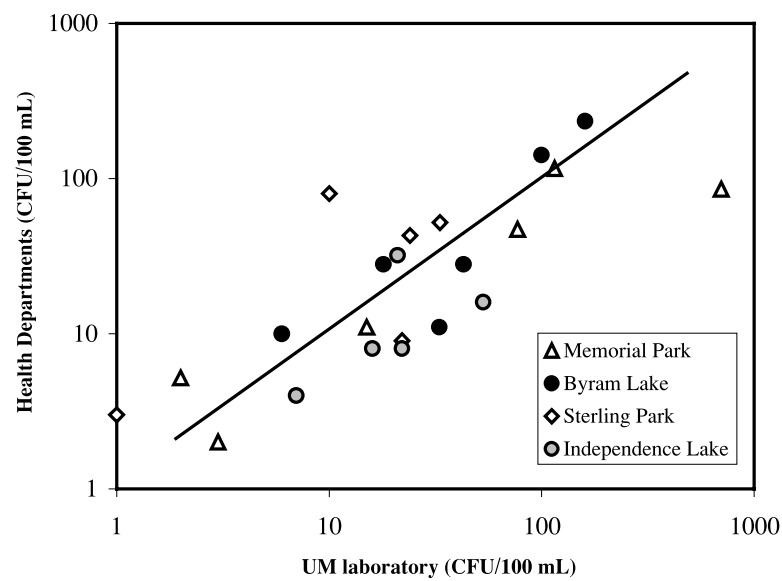

Figure 2. A comparison of the E. coli plate counts between the cooperating health departments and the University of Michigan (UM).

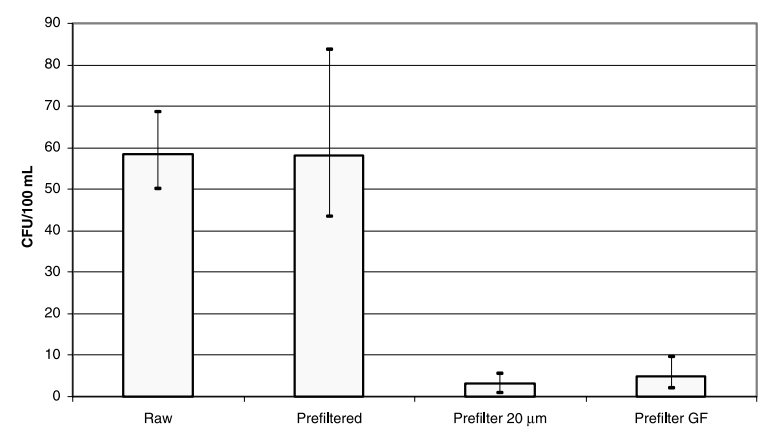

Figure 3. E. coli in the original water sample, prefiltered water, and remaining on the prefilter membranes.

ance of turbidity removal while not trapping bacteria. For this, turbidity and E. coli concentration were measured before and after the prefiltration step with a turbidometer and $\mathrm{m}$-TEC during the initial phase of the study. Among the tested prefilters, which included a glass fibre filter, a $5 \mu \mathrm{m}$ pore size nylon filter and a $20 \mu \mathrm{m}$ pore size nylon filter, a $20 \mu \mathrm{m}$ pore size filter was chosen. Figure 3 shows the $E$. coli concentrations in the original water sample, in the prefiltered $(20 \mu \mathrm{m}$ pore size filter) water sample, and E. coli remaining on the prefilters $(20 \mu \mathrm{m}$ pore size filter and glass fibre filter $)$. It was found that almost all the bacteria ( $>95 \%$ ) could pass through the prefilter while the turbid materials were trapped onto the prefilter, and that the proportion of E. coli remaining on the surface of the prefilter was negligible.

The filtered water volume during the early phase of the study was $200-500 \mathrm{~mL}$, whereas later tests employed $100-200 \mathrm{~mL}$, which was sufficient for the analysis. The reduced volume was due to the improvement in the recovery method and the separation step. For the recovery of bacteria from the membrane filter, two methods, back-flush and resuspension, were tested with 


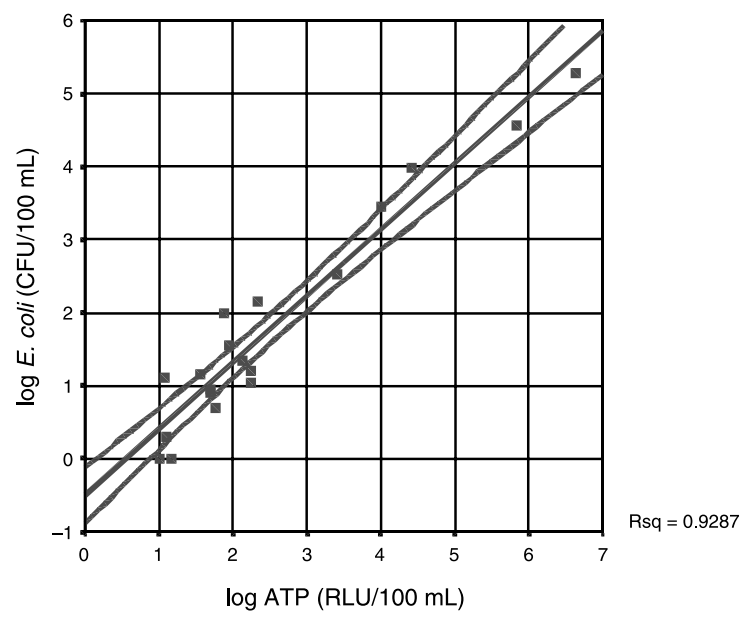

Figure 4. The relationship between ATP (RLU) and plate count (CFU) with $95 \%$ mean prediction intervals.

E. coli-seeded water samples. Both methods were equally efficient ( $t$-test, $p<0.05$, data not shown). The detection limit of the assay was about 20 CFU/100 mL, which is lower than the EPA beach water standards of 126 (30 day average) and $300 \mathrm{CFU} / 100 \mathrm{~mL}$ (single sample). The low detection limit could have been obtained due to the successful concentrating procedure.

Figure 4 illustrates the relationship between the IMSATP results and the membrane plate count results in determining $E$. coli levels from the beach samples. The relationship between the ATP assay and the plate counts $(n=24)$ is: $\log \mathrm{CFU} / 100 \mathrm{~mL}=0.91 * \log \mathrm{RLU} / 100 \mathrm{~mL}$ -0.503 . A larger amount of data is needed to have more statistically sound correlation between the IMS-ATP bioluminescence results and the colony-forming units. The regression equation can be changed as the size of data increases in the future and the testing procedure modifies.

The IMS-ATP bioluminescence method in beach waters for detecting $E$. coli offers advantages over current membrane filtration methods. The IMS-ATP method is very fast and sensitive. In addition, the method is capable of detecting $E$. coli that is difficult to grow on selective agar medium. Bacteria in natural environment are often starved, stressed or injured, due to exposure to suboptimal growth conditions, and these bacteria are viable but cannot grow well on agar plates (14). However, the injury does not directly affect the presence of intracellular ATP (15). During our experiments, important control measures were employed to prevent false-positive results, i.e. prefiltration, thorough washing, treatment with somatic cell releasing agent, disinfection of the magnetic beads before coating, use of blank control, etc.

For the specificity test of the immunomagnetic capture, bacterial strains were confirmed using Riboprinter and API 20E. The separated bacteria by IMS were identified as E. coli in most cases ( $>90 \%)$. However, Yersinia enterocolitica, Vibrio alginolyticus, Shigella spp. and Serratia plynuthica were also found. This may be due to the cross-reactivity of the polyclonal antibody. The IMS-ATP bioluminescence procedure was tested on-site at Independence Lake and Lake St. Clair beach.

\section{CONCLUSIONS}

This study demonstrates that IMS combined with ATP bioluminescence is an effective and expedient method for detecting $E$. coli in beach water. The entire procedure takes less than 1 hour without an enrichment step. The detection limit is about $20 \mathrm{CFU} / 100 \mathrm{~mL}$, which is well below the action limits of $300 \mathrm{CFU} / \mathrm{mL}$ (daily event), or a 30 day moving average of $126 \mathrm{CFU} / 100 \mathrm{~mL}$ set by US EPA. The antibodies coated on the beads may cross-react with some other enteric bacteria, so that the actual number estimated may be slightly higher than that for $E$. coli alone. Future research will focus on utilizing a mixture of antibodies for detection of multiple coliform groups and further improvement in the procedure. This method can be used as a platform technique for determining other indicator organisms in recreational water using antibodies against target organisms (e.g. enterococci).

\section{Acknowledgements}

We thank Arvil Ancheta for assisting with E. coli testing and the filtration study. We greatly appreciate the cooperation and support from the health departments of Genesee (Nickolas Hoffman, Brian McKenzie), Macomb (Elwin Coll, Gary White), Monroe (Christopher Westover) and Washtenaw counties (Richard Badics, Bradley Bucklin) in Michigan. We also thank Professor Peter Meier for his helpful review of the manuscript. This study was supported in part by the Michigan Great Lakes Protection Fund of the Michigan Department of Environmental Quality under Grant No. GL 00-059.

\section{REFERENCES}

1. US Environmental Protection Agency. Ambient Water Quality Criteria for Bacteria (EPA 440/5-84-002). Washington DC: EPA, 1986.

2. APHA, AWWA, WEF. Standard Methods for the Examination of Water and Wastewater, 20th edn. New York: APHA, 1998.

3. Iqbal S, Robinson J, Deere D et al. Efficiency of the polymerase chain reaction amplification of the uid gene for detection of Escherichia coli in contaminated water. Lett. Appl. Microbiol. 1997; 24: 498-502.

4. Regnault B, Martin-Delautre S, Lejay-Collin M, Lefevre M, Grimont PAD. Oligonucleotide probe for the visualization of Escherichia coli/Escherichia fergusonii cells by in situ hybridezation: specificity and potential application. Res. Microbiol. 2000; 151: 521-533. 
5. Van Poucke SO, Nelis HJ. A 210-min solid phase cytometry test for the enumeration of Escherichia coli in drinking water. J. Appl. Microbiol. 2000; 89: 390-396.

6. Rompre A, Servais P, Baudart J, de-Roubin M-R, Laurent P. Detection and enumeration of coliforms in drinking water: current methods and emerging approaches. J. Microbiol. Methods 2002; 49: $31-54$.

7. Grimont PAD, Regnault B, Delautre S, Villarino A. Advances in microbiological monitoring and rapid detection-bacterial detection by in situ hybridization. Wat. Supply 2000; 18(1): 443-446.

8. Way JS, Josephson KL, Pillai SD et al. Specific detection of Salmonella spp. by multiplex polymerase chain reaction. Appl. Environ. Microbiol. 1993; 59: 1473-1479.

9. Höller C, Koschinsky S, Witthuhn D. Isolation of enterohaemorrhagic Escherichia coli from municipal sewage. Lancet 1999; 353(9169): 2039.
10. Pyle BH, Broadway SC, McFeters GA. Sensitive detection of Escherichia coli $\mathrm{O} 157: \mathrm{H} 7$ in food and water by immunomagnetic separation and solid-phase-laser cytometry. Appl. Environ. Microbiol. 1999; 65(5): 1966-1972.

11. Tan W, Shelef LA. Automated detection of Salmonella sp. in foods. J. Microbiol. Methods 1999; 37: 87-91.

12. Lee J, Deininger RA. A rapid method for detecting bacteria in drinking water. J. Rapid Methods Autom. Microbiol. 1999; 7(2): $135-145$.

13. Van der Kooij D et al. Biofilm formation on surfaces of glass and Teflon exposed to treated water. Wat. Res. 1995; 29: 1655-1662.

14. Byrd JJ, Xu H, Colwell RR. Viable but nonculturable bacteria in drinking water. Appl. Environ. Microbiol. 1991; 57(3): 875-878.

15. Little KJ, La Rocco KA. ATP screening method for presumptive detection of microbiologically contaminated carbonated beverages. J. Food Sci. 1986; 51(2): 474-476. 